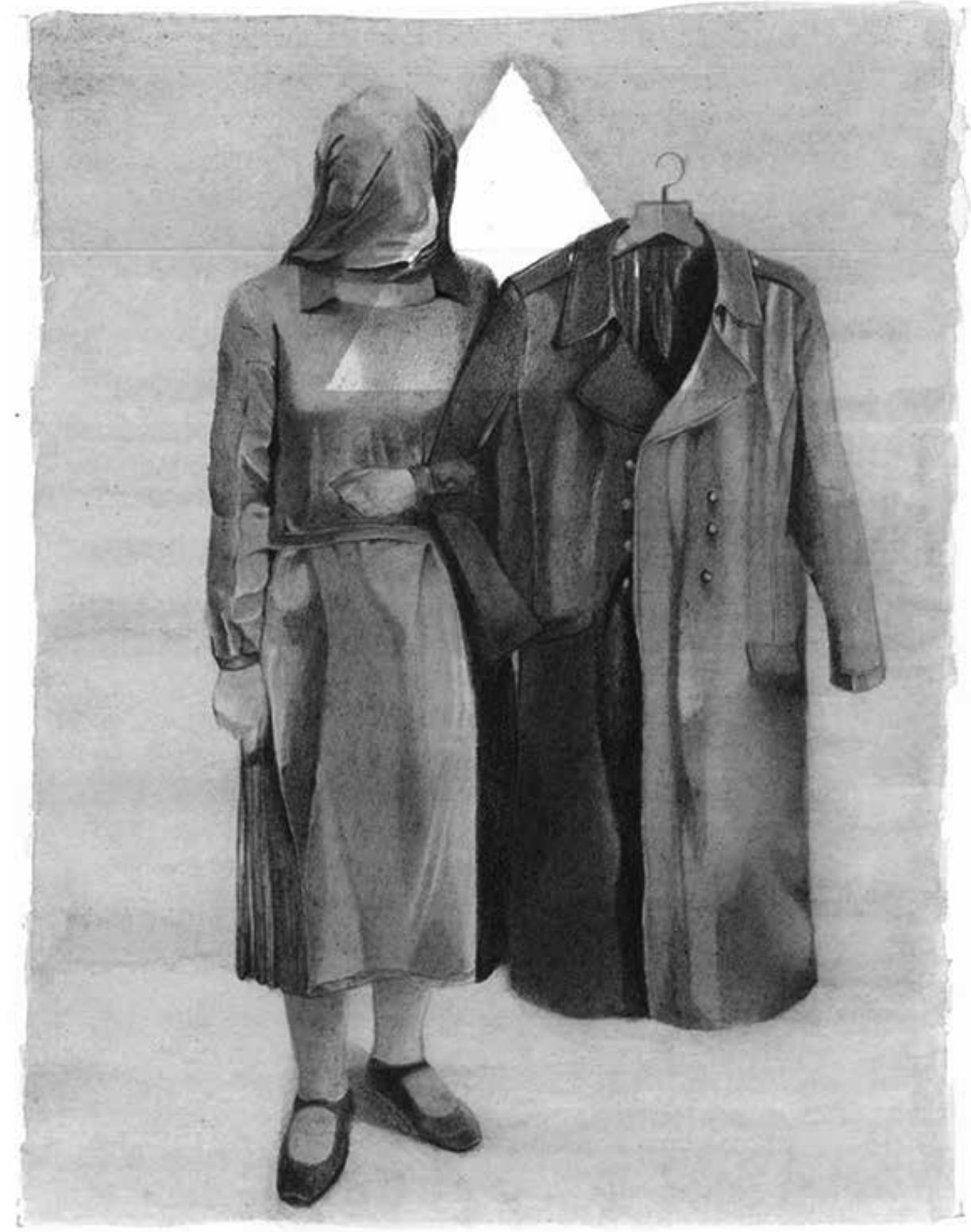

Luis Fernando Salazar Espinosa

Sin título

Lápiz sobre papel

$18 \times 15 \mathrm{~cm}$

2017

Medellín 


\title{
Gobernabilidad migratoria, ¿ reforzando el modelo de securitización en Suramérica? El éxodo venezolano y sus retos para el Estado colombiano*
}

\author{
Alejandra León Rojas (Colombia)**
}

\section{Resumen}

El artículo cuestiona el modelo de gobernabilidad migratoria adoptado por Suramérica en su propósito de hacerle frente al éxodo masivo venezolano. Algunos países de la región han optado por controlar la migración a través de la militarización fronteriza, adoptando posturas securitistas que se suman a la tendencia global de asumir las migraciones como un problema. A partir de una revisión documental de artículos de prensa e investigaciones cualitativas, y de la revisión de las páginas web de organismos internacionales y nacionales el texto busca generar reflexiones sobre la necesidad de tomar medidas más coordinadas entre países y continuar con las premisas expuestas en el referente de gobernabilidad migratoria de la región: la Conferencia Suramericana sobre Migraciones (CSM), en el que prima el respeto por los derechos humanos de los migrantes. Asimismo, expone algunos de los retos del

Estado colombiano como uno de los mayores receptores de migración del vecino país.

\section{Palabras clave}

Migración; Gobernabilidad Migratoria; Políticas Públicas; Seguridad; Derechos Humanos; Suramérica.

Fecha de recepción: abril de 2019

- Fecha de aprobación: septiembre de 2019

\section{Cómo citar este artículo}

León Rojas, Alejandra. (2020). Gobernabilidad migratoria, ¿reforzando el modelo de securitización en Suramérica? El éxodo venezolano y sus retos para el Estado colombiano. Estudios Políticos (Universidad de Antioquia), 57, pp. 210-228. DOI: 10.17533/udea.espo.n57a10

\footnotetext{
* Una versión de este texto se presentó en el Seminario Internacional Democracia y Dinámicas Subnacionales en México y América Latina en Cuidad de México, organizado por el Instituto de Investigación Dr. José María Mora y la Universidad Autónoma de la Ciudad de México del 5 al 10 de diciembre de 2018.

** Filósofa. Magíster en Gobierno y Políticas Públicas. Integrante del Grupo de Investigación en Filosofía Política (GIFP), Instituto de Filosofía, Universidad de Antioquia. Correo electrónico: alejandra.leonr@udea.edu.co - Orcid: 0000-0003-2016-6529 - Google Scholar: https://scholar.google. es/citations?hl=es\&user=76loV7gAAAAJ
} 


\title{
Migratory Governability, Reinforcing the Securitization Model in South America? The Venezuelan Exodus and its Challenges for the Colombian State
}

\begin{abstract}
The article challenges the model of migration governance adopted by South America to face the Venezuelan mass exodus. Some countries in the region have opted to control migration through border militarization, assuming securitist policies and meassures that add to the global tendency to assume migrations as a problem. Therefore, the text reflect on the need to take more coordinated measures among countries and to continue with the premises outlined in the region governance reference: The South American Conference on Migrations (SACM), in which respect for the human rights of migrants prevails. Also, it exposes some of the challenges of the Colombian State, as one of the largest recipients of migration from the neighboring country.
\end{abstract}

\section{Keywords}

Migration; Migration Governability; Public Politics; Security; Human Rights; South America. 


\section{Introducción}

Para la década de 1990, la denominada «migración irregular» se posicionó en las agendas mundiales de la Unión Europea, la OCDE, la OIM, entre muchas otras agencias, convirtiéndose, junto al comercio de armas, el tráfico de drogas y el crimen organizado, en una preocupación internacional (Düvell, 2008). Desde entonces, los discursos sobre inmigración orientaron los debates políticos y sociales alrededor del mundo, ganando atención prioritaria después de los acontecimientos del 11 de septiembre de 2001 y dando lugar a una creciente necesidad de controlar las fronteras y de reducir los costos que suponía este tipo de desplazamiento para las sociedades de mayor recepción. Esto supuso una transformación significativa en materia de legislación y política migratoria que constituiría una especie de gobernabilidad migratoria «adoptada y resignificada según las particularidades de cada contexto político nacional» (Domenech, 2013, p. 3).

Algunos de los modelos más representativos e implementados plantean, por ejemplo, desde una postura ética, situar en el centro de toda política migratoria los derechos de los migrantes — modelo de desarrollo humano-, mientras que, para otros, resulta prioritario establecer una lucha transversal

[212] en contra de la migración irregular — modelo de la securitización-. Desde esta última perspectiva, la movilidad humana debe ser gobernada por medio de instrumentos político-jurídicos que transforman el régimen de control fronterizo en una herramienta de protección en contra de las «nuevas amenazas transnacionales»: «la amenaza migrante» (Campesi, 2012; Naranjo, 2014). Con lo anterior, prevalece la visión que criminaliza la permanencia de los migrantes ilegales o irregulares bajo el pretexto de que estos representan competencia desleal en el mercado de trabajo, aumentan la criminalidad urbana o desarrollan otras prácticas que amenazan la cohesión social.

En este sentido, el argumento principal para su control o regularización no es otro que «la supervivencia de la sociedad y, por lo tanto, el mantenimiento de sus características identitarias, económicas y sociales básicas» (Campesi, 2012, p. 5). Esta orientación defensiva no solo hace más evidente el nexo entre migración y seguridad, sino que, al tiempo, transforma los temores e inseguridades sociales en retórica discursiva para excluir, rechazar y señalar a los migrantes irregulares como potenciales enemigos del orden público y la estabilidad de las comunidades políticas de acogida (Solanes, 2005). 
Sin embargo, estas discursividades no se quedan sobre la base de prácticas sociales discriminatorias, sino que calan en acciones y políticas concretas de los Estados nacionales securitistas que transforman sus fronteras territoriales en mecanismos del control migratorio. Este cambio se ha vuelto evidente en realidades discursivas que interpretaron la movilidad de personas en términos de invasión y de conflicto como, por ejemplo, «la política de la alambrada» en la Unión Europea, «los muros de separación» tanto en el sur del Mediterráneo como para las fronteras entre Estados Unidos y México (Zapata-Barrero y Van Dijk, 2007) y, más propiamente, en las denominadas «jaulas» para hijos de inmigrantes centroamericanos indocumentados como materialización de la política migratoria «tolerancia cero».

Simultáneamente, en una lógica de control y cooperación, y complementando el nexo entre migraciones y seguridad, la desterritorialización de fronteras y la externalización de las políticas migratorias son otros de los enfoques que caracterizan las políticas contemporáneas de gestión de los flujos irregulares de personas. Ambos describen las acciones estatales extraterritoriales que pueden implicar la participación directa, bilateral o multilateral de los Estados en su propósito por contener y prevenir la inmigración irregular en sus fronteras legales o territoriales (Naranjo, 2014; Podkul y Kysel, 2015). En la práctica, desterritorialización y externalización pretenden contrarrestar la ineficacia de las políticas de migración doméstica y el control fronterizo, acudiendo al compromiso sistemático con terceros países - emisores o de tránsito-. El propósito es abordar las «causas fundamentales» que llevan a los migrantes a abandonar sus comunidades y a poner en peligro sus vidas, al tiempo que reducen la presión migratoria sobre los Estados de destino (Podkul y Kysel, 2015), a través de acuerdos económicos y comerciales por transferencia de responsabilidades con los migrantes.

No obstante, este tipo de políticas y prácticas fronterizas afectan los derechos humanos de los migrantes, al no hacer claras las obligaciones de los Estados para protegerlos. En muchos casos, la responsabilidad es transmitida a los países que cooperan, generándoles cargas onerosas que deben cubrir con menos recursos y sujetos —en la práctica y por ley- a garantizar la protección de los derechos de los migrantes (Mirra, 2018; Podkul y Kysel, 2015). Ahora bien, para los críticos de la gobernabilidad migratoria y sus políticas restrictivas, estas han logrado, a lo sumo, «controlar la migración regular, pero han producido la más grande acumulación de personas en situación irregular de todos los tiempos» (Mármora, 2010, p. 73). Esto refleja 
la impotencia de los gobernantes frente a un fenómeno que los sobrepasa y cuyas medidas parecen desconocer que cruzar fronteras se ha transformado en un asunto de vida o muerte para millones de seres humanos.

Siguiendo esta reflexión, el artículo se ocupa, primero, de cuestionar la existencia de una gobernabilidad migratoria en Suramérica, pese a la existencia de la Conferencia Suramericana sobre Migraciones (CSM) como principal proceso consultivo en la región en materia migratoria, dado el desafío que representan los movimientos poblacionales de los últimos años, especialmente, los de venezolanos y que ha impulsado la creación de instancias ad hoc como el «Proceso de Quito»; ${ }^{1}$ y segundo, plantear los retos que tiene el Estado colombiano frente al éxodo venezolano, teniendo en cuenta algunos de los mecanismos que ha implementado para gestionar los flujos de población venezolana.

La investigación se ha centrado en la revisión documental de artículos de prensa e investigaciones cualitativas para la construcción conceptual y para sustentar algunos procesos referidos a las migraciones venezolanas; asimismo, se recurrió a las páginas web de organismos internacionales como la Organización Internacional para las Migraciones (OIM) y la Agencia de la

[214 ] ONU para los Refugiados (Acnur), y de organismos estatales como Migración Colombia.

\section{Gobernabilidad migratoria en Suramérica}

La institucionalización de la CSM, con el apoyo técnico de la OIM, puede considerarse un referente para el desarrollo de la gobernabilidad migratoria en Suramérica. ${ }^{2}$ Este es el proceso consultivo regional más importante en materia migratoria, pues abarca a todos los países de la región y está orientado a «generar y coordinar iniciativas y programas dirigidos a promover y desarrollar políticas sobre las migraciones internacionales y su relación con el desarrollo y la integración regional» (CSM-Osumi, s. f. a). A través de su instauración, la región suramericana ha optado por «la búsqueda del diálogo entre diferentes

\footnotetext{
${ }^{1}$ Instancia multilateral que se estableció tras la Declaración de Quito sobre movilidad humana de ciudadanos venezolanos en la región en septiembre de 2018, en la que participan catorce países, entre ellos, siete suramericanos - Argentina, Brasil, Chile, Colombia, Paraguay, Perú y Uruguay- y que cuenta con el apoyo de la OIM y la Acnur.

${ }^{2}$ Cabe aclarar que el concepto de gobernanza migratoria se introduce en la XII CSM, Santiago de Chile, 2012, y se desarrolla en conferencias posteriores: XIII CSM, Cartagena, 2013, y xIV-CSM, Santiago de Chile, 2015 (CSM-Osumi, s. f. b).
} 
actores y bajo la égida del respeto por los derechos de los migrantes» como principio rector (Martínez, 2001, p. 90), especialmente en lo que respecta a su libre circulación y residencia. Lógicamente, el enfoque parte de la comprensión de que los doce países miembros se han caracterizado por ser, principalmente, de emigración hacia Estados Unidos y Europa, así como de migración intrarregional (Estupiñán, 2013).

A partir de la CSM y el plan de acción adoptado en 2009, la región se ha centrado en generar espacios de intercambio sobre asuntos migratorios y a cuestionar el «aumento de los dispositivos de control y sanción, así como por el recorte de derechos humanos en la nacionalidad o la condición migratoria de las personas en los países de destino» (Ceriani, 2011, p. 69). De este modo, las iniciativas han convivido con las normas que criminalizan la migración irregular, mientras abogan por otras más reformistas que atiendan las causas de la migración. Esto ha implicado la comprensión de los distintos papeles que cumple la persona migrante, así como la necesidad de una respuesta articulada de la institucionalidad regional a los movimientos migratorios (Mármora, 2010). En este sentido, las políticas han intentado vincular posibilidades de desarrollo de las comunidades de origen y han buscado estrechar relaciones con las respectivas diásporas por medio de mecanismos económicos, políticos y culturales (Araujo y Eguiguren, 2009), al tiempo que advierten sobre la necesidad de adoptar medidas para cumplir los compromisos internacionales en materia de derechos de los migrantes (Ceriani, 2011).

No obstante, una serie de cambios se han estado gestando en el panorama migratorio que, en lugar de constituir una postura unívoca como la planteada por la CMS y la OIM en la región frente a las migraciones, «dan cuenta de una verdadera crisis de gobernabilidad en este sentido o, por lo menos, la adopción de una postura que, más bien, se asimilan al enfoque restrictivo que se cuestiona en países de otras latitudes» (Ceriani, 2011, p. 70). La inestabilidad económica, política y social que atraviesa Venezuela, la cual ha provocado un aumento en la movilidad de venezolanos, evidencia que las normativas y prácticas suramericanas no se encuentran preparadas para afrontar plenamente este tipo de fenómenos. Si bien esta situación ha llevado a que varias naciones — no solo de América Latina- debatan sobre las medidas necesarias para afrontar el éxodo venezolano, acogiendo, en teoría, enfoques concordantes con el respeto a los derechos humanos de los migrantes y con la visión de fronteras abiertas que permita su libre circulación. Como lo especifican los instrumentos internacionales y regionales 
aplicables, cada país ha implementado medidas individuales, dado el temor a desbordar sus sistemas locales y a la generación de brotes xenófobos. Esta situación muestra poca unidad en la práctica frente a cómo asumir la llegada de migrantes a las fronteras y ha dado lugar a la aparición de diferentes medidas legales por parte de varios Estados.

Diego Acosta, Cécile Blouin y Luisa Freier (2019, pp. 6-13) identifican al menos seis grupos de Estados, según el tipo de medidas legales adoptadas ante la llegada de migrantes venezolanos en América Latina: a) aquellos que han decidido usar su propia normatividad de manera extensiva para incluir a los venezolanos; b) aquellos que han creado una normatividad específica; c) los que no han adoptado medida alguna; d) los que han otorgado estatus de refugiado a partir de la definición ampliada de la Declaración de Cartagena de 1984; e) los que han optado por un programa de regularización; y f) los que han criminalizado a la población venezolana.

Así pues, han primado medidas discrecionales que se traducen en permisos de residencia especiales, de carácter temporal y que no implican, propiamente, la autorización de residencia permanente. A esto se le suma que, si bien la población venezolana ha optado por una migración interregional,

[216] las dificultades en la obtención de permisos han sido más complejas en unos países que en otros por la exigencia de ciertos requisitos con los que no cuenta la población migrante, lo cual explica, entre otras cosas, las grandes diferencias en el número de personas acogidas. Esta situación abre interrogantes sobre la apertura de los Estados suramericanos y cuestiona a la CSM como instancia guía para la orientación política de los gobiernos en Suramérica (Mármora, 2016), así como la aparición de instancias ad hoc como el «Proceso de Quito» ${ }^{3}$ en respuesta a la crisis migratoria de Venezuela.

Países como Perú y Ecuador, que han acogido 863613 y 385042 migrantes y refugiados, respectivamente (Acnur, 2019, junio 7), optaron por medidas restrictivas ante la inmigración venezolana y empezaron a exigir el pasaporte, en lugar de la cédula de identidad, como requisito para entrar

\footnotetext{
${ }^{3}$ Cabe aclarar que el surgimiento de una instancia como esta da cuenta de que el fenómeno migratorio venezolano ha desbordado la capacidad de respuesta de los países que han recibido un mayor impacto por el flujo de migrantes, lo que puede explicar que se hayan agrupado, dejado de lado las recomendaciones de la CSM para actuar de manera focalizada sobre las problemáticas y las soluciones que surgen del flujo migratorio de población procedente de Venezuela en sus territorios.
} 
a sus territorios y reducir los problemas de seguridad en las fronteras. El Gobierno peruano, a través de la Superintendencia Nacional de Migraciones, impuso la obligatoriedad del pasaporte para el ingreso de venezolanos en 2018 (Resolución 000270-2018 del 24 de agosto de 2018) y, a principios de 2019, el Gobierno ecuatoriano añadió como exigencia de ingreso a los venezolanos a su territorio los antecedentes apostillados a través del Acuerdo Interministerial 0000001 del 21 de enero de 2019.

Una de las dificultades que se viven en Venezuela es la obtención de documentos oficiales como el pasaporte y los antecedentes judiciales, empero, estos se han transformado en requerimientos que exigen los países de acogida para poder regularizar a la población migrante.

Muchos migrantes venezolanos no cuentan con documentos adecuados, pues las autoridades del gobierno de Nicolás Maduro imponen trabas para la expedición de estos documentos, algo que no permite al ciudadano venezolano muchas veces contar con su cédula de identidad o un pasaporte que le permita desplazarse hacia otros países (Mesa, 2019, julio 28).

La dificultad para obtener estos documentos incrementa la vulnerabilidad y la precariedad de los migrantes al dejarlos expuestos al tráfico de personas y a redes que se aprovechan de sus necesidades y de su condición irregular para embarcarlos en actividades ilegales. La ausencia de documentación o algún permiso de permanencia regular en Estados cercanos hace a los migrantes venezolanos particularmente vulnerables a la explotación laboral y sexual, al tráfico de personas, a la violencia, a la discriminación y a la xenofobia (Acnur, 2019, junio 7).

Por su parte, países como Argentina, con un aproximado de 145000 migrantes venezolanos, han mostrado interés en mantener una política abierta ante la migración venezolana, mientras que Chile, con 371163 migrantes, creó mecanismos de regularización de carácter más restrictivo, como «la visa de responsabilidad democrática», para garantizar el ingreso «ordenado y seguro» a migrantes venezolanos y haitianos (Acnur, 2019, junio 7). Para su obtención es necesaria «la presentación de certificados de antecedentes penales debidamente apostillados por el Ministerio Popular de Relaciones Exteriores (con vigencia de tres meses) y el pasaporte vigente con 18 meses 
de validez» (Acosta, Blouin y Freier, 2019, p. 8). En el caso de Brasil, ${ }^{4}$ con 224 102 migrantes venezolanos (Acnur, 2019, junio 7), las políticas de inmigración y refugiados enfocadas al respeto de los derechos humanos, la reunificación familiar y el acceso a programas sociales, recaen en nudos burocráticos $y$, junto a las presiones regionales por la inmigración, donde la población limitada económicamente es renuente a recibir vecinos venezolanos, dejan expuestos a los migrantes a condiciones precarias de trabajo y a la esclavitud.

Colombia es, quizás, el país menos preparado de la región para atender este fenómeno (Acosta, Blouin y Freier, 2019) y se encuentra frente a una oleada migratoria que supera la población de algunas de sus capitales. Su postura ha pretendido facilitar el ingreso de los vecinos, pero tratando de formalizarlos. Sin embargo, este ha sido más un país de emigración que de inmigración, por lo que su infraestructura logística, política e internacional se ha configurado acorde con este hecho. En todo caso, centenares de venezolanos cruzan las fronteras, legal o ilegalmente, ya sea para instalarse en el país o como puente para llegar a otros Estados, y aunque es claro que Colombia se encuentra ante una crisis que desborda sus previsiones y capacidades, la militarización de sus fronteras no solo desincentiva el derecho a migrar, sino que no atiende las causas que llevan a estas personas a desplazarse; además de exponer a los migrantes a grupos armados ilegales, narcotraficantes y bandas locales que ejercen controles en las fronteras.

Desde inicios del 2018 se han realizado controles fronterizos más restrictivos de la movilidad, con mayor presencia del ejército en la frontera. [Se] adelantan procedimientos de verificación y operativos en parques y centros comerciales que derivan en la sanción, deportación y expulsión, sin que existan alternativas efectivas para la regularización (Codhes, 2018).

De este modo y en términos generales, las políticas restrictivas aparecen como las medidas más adecuadas para controlar la migración a través de la militarización fronteriza, adoptando posturas securitistas que se suman a la tendencia global de asumir las migraciones como un problema. Por ello, siguiendo esta línea, resulta preciso estrechar las fronteras y crear mayores barreras para desincentivar la migración (Milanovic, 2017). A esto se le suma la retórica de algunos políticos de la región que, en lo local, generan tensiones

${ }^{4}$ A principio de 2019, Brasil abandonó el Pacto Mundial Sobre Migraciones de la ONU, bajo el argumento de garantizar una migración ordenada y brindar protección a extranjeros y locales (El Mundo, 2019, enero 9). 
entre nativos y extranjeros, dando lugar al surgimiento de la discriminación xenófoba y a dinámicas que constituyen violaciones sistemáticas a los derechos humanos de las personas migrantes. Mientras esto sucede, los migrantes se ven abocados a buscar nuevas rutas de tránsito que amenazan su seguridad y que resultan determinantes en el aumento de personas en situación irregular.

En Ecuador, el presidente ecuatoriano Lenín Moreno, luego de un incidente en la comunidad de Ibarra, endureció los controles fronterizos en su país y anunció, vía Twitter, la conformación de brigadas para controlar la situación de los migrantes en las calles y en los lugares de trabajo. Esto desencadenó que muchos venezolanos fueran víctimas de agresiones por parte de grupos de ciudadanos que los desalojaron violentamente de albergues y residencias (León, 2019, enero 28). Meses atrás, una situación similar se presentó en Brasil, específicamente en Paracaima, donde algunos pobladores prendieron fuego a las pertenencias de algunos venezolanos asentados en campamentos luego de que se desatara el rumor de que algunos de estos habían intentado asaltar a un comerciante (BBC, 2018, agosto 20).

Dada la aparición de formas más burdas de detener físicamente la migración, resulta imperativo preguntarse si este problema debe resolverse o, por lo menos, abordarse de una mejor manera de la que se ha seguido hasta ahora (Milanovic, 2017, p. 170). La experiencia europea y su voluntad de controlar los flujos migratorios «han creado la imagen de una Europa a la defensiva, que se encierra en sí misma y que diferencia de forma radical a los ciudadanos comunitarios de aquellos que no lo son» (Mayeur, 1997, p. 20); además de que ha emprendido la lucha contra la migración irregular, criminalizándola y generando desconfianza al extranjero, lo que se potencia en actitudes xenófobas y nacionalistas en la opinión pública (Mayeur, 1997).

Por ello, Suramérica debe recoger esos aprendizajes y afrontar grandes retos a la hora de dar una respuesta a la crisis que plantea el éxodo venezolano. La solución no debe radicarse en medidas unilaterales y desde una lógica nacional, que no solo resultan ineficaces, en virtud de la negación de la complejidad del fenómeno, sino también corrosivas, al establecer relaciones de desconfianza entre países y agudizar el drama humanitario, como se ha venido presentando. Al contrario, es necesario trabajar coordinadamente, pese a las diferencias, en el ámbito multinacional y con el firme propósito de garantizar los derechos humanos de quienes se esfuerzan por empezar de nuevo en un contexto adverso (Sassen, 2003). 


\section{Retos del Estado colombiano ante las migraciones masivas venezolanas}

Colombia no tiene una experiencia migratoria como la pueden tener otros países suramericanos. Factores económicos, políticos y sociales dificultaron su proyección como un destino de inmigración y constituyeron detonantes para que se convirtiera en un país de emigración. Los diferentes flujos de población colombiana emigrada se situaron en diferentes épocas, con destinos y motivaciones muy específicas. Por ejemplo, entre las décadas de 1960 y 1970 el destino era Estados Unidos, ante la posibilidad de acceder a mejores oportunidades laborales, dada la necesidad de migración de mano de obra calificada. Para las décadas de 1970 y 1980, la bonanza petrolera en Venezuela dio como resultado una coyuntura especial para los inmigrantes, particularmente colombianos. Mientras que en la década de 1990 la crisis política y económica, sumada a la agudización del conflicto armado interno y el narcotráfico dieron lugar a una tercera oleada a Europa, especialmente con dirección a España (Álvarez, 2004; Mejía, 2012).

En el caso de la migración de colombianos hacia Venezuela, este se prolongó por casi tres décadas, de manera progresiva, sin alterar la estabilidad [220] y crecimiento económico del que gozaba para entonces el vecino país. Sin embargo, el desplome de los precios del petróleo y la disminución de exportaciones redujeron drásticamente el flujo migratorio de colombianos y algunos decidieron retornar, aunque no de manera acelerada dado, el panorama político, social y económico por el que entonces atravesaba el país (Mejía, 2012). Posteriormente, esto cambió y Venezuela volvió a ser atractiva para los migrantes colombianos de escasos recursos en la década de 2000, gracias a los incentivos en materia social que brindaba el gobierno de Hugo Chávez.

Por su parte, la oleada de migrantes venezolanos hacia Colombia puede considerarse un fenómeno opuesto. En menos de tres años, el flujo de personas que llegan desde Venezuela ha sido masiva. Se estima que la cantidad de refugiados y migrantes venezolanos supera los cuatro millones, siendo Colombia, con más de 1.4 millones, el país que más alberga, seguido por Perú, con 863613 y Ecuador con 385042 (Acnur, 2019, junio 7). Es importante resaltar que muchas de estas personas también son colombianos retornados o expulsados desde Venezuela. En este sentido, están intentando reintegrarse y mejorar las condiciones que los llevaron a cruzar las fronteras. 
Para que esto sea factible, Colombia tiene que asumir varios retos para afrontar el éxodo venezolano y, de esta manera, generar acciones que permitan, paulatinamente, la integración de migrantes a la sociedad colombiana. Paralelamente, el país deberá atender profundos conflictos que lo aquejan: la polarización tras los Acuerdos de Paz, los graves casos de corrupción que afectan la institucionalidad, la poca presencia del Estado en muchas regiones, así como las desigualdades sociales y la pobreza extrema que generan un ambiente de zozobra entre los locales y puede ser caldo de cultivo para reacciones xenófobas, al considerar la presencia de los migrantes venezolanos como una amenaza más en su complejo panorama. Es importante resaltar que los migrantes no pueden cargar con la culpa de la ausencia del Estado en muchos de los territorios a los que llegan, estos, a lo sumo, actúan como catalizadores de tensiones locales ya existentes.

Ahora bien, son muchos los retos no solo del Estado colombiano, sino de Suramérica para afrontar la migración masiva de venezolanos, que dependerá de una agenda de trabajo articulado que permita extender la reflexión sobre el deber de brindarle acogida a seres humanos que no tuvieron otra opción que cruzar fronteras. Abordar una crisis no es fácil, la región carece de respuestas institucionalizadas y ninguna sociedad está preparada para los escenarios que imponen los desplazamientos masivos de personas. Sin embargo, es la unión de voluntades, en todos los ámbitos, la que permitirá hacerle frente a este y otros flujos migratorios en el futuro. Lo anterior será el primer eslabón para que la integración de la comunidad venezolana a los países receptores no se quede en un asunto meramente formal, sino que trascienda hacia el goce efectivo de los derechos, el intercambio de valores y prácticas, así como el acceso a oportunidades por parte de los migrantes. Así pues, algunos de los retos que deberán ser abordados por Colombia con el firme propósito de revertir la condición de vulnerabilidad de los migrantes son:

En el ámbito global, es necesario que siga cuestionando las políticas migratorias restrictivas de los Estados más securitistas en su tratamiento de la migración irregular, las cuales son una clara expresión de xenofobia y vulneración a los derechos humanos. Es fundamental hacer parte de visiones más reformistas que tengan como eje rector el respeto por los derechos de los migrantes, como lo expresan los modelos e instrumentos de gobernabilidad migratoria de las instancias creadas con tal propósito en Latinoamérica y El Caribe. 
En el ámbito suramericano, Colombia debe impulsar el trabajo articulado entre los países de la región, acudiendo al compromiso de los gobiernos con el fin de hacerle frente a la oleada migrante de venezolanos. Para ello es necesario unificar criterios para el tratamiento de los migrantes a través de las fronteras, evitando su cierre y brindando ayuda humanitaria, mientras a través de instancias como la CSM, por ejemplo, se discutan mecanismos que puedan, a largo plazo, responder más y mejor al éxodo venezolano y a futuros flujos migratorios. Es comprensible que la instauración del «Proceso de Quito» y la participación del Gobierno colombiano en su mesa técnica regional ha buscado actuar articuladamente con aquellos Estados que se han visto mayormente impactados con la llegada de ciudadanos de Venezuela, a través del intercambio de experiencias y la puesta en común de legislaciones, capacidades y recursos: [El Proceso de Quito] ha emitido declaraciones conjuntas en las que se reafirma el objetivo principal de conseguir una estrategia para garantizar una migración segura, ordenada y regular. Más allá de eso no se destaca ninguna operación. Uno de los principales obstáculos es por el problema de recursos (El Espectador, 2019, noviembre 14). No obstante, esto no puede considerarse un ejercicio aislado ante los avances de la CSM, al contrario, representa la profundización en los mecanismos y compromisos para atender a los migrantes, en la que el país debe asumir la crisis migratoria como una oportunidad para reafirmar su compromiso con mejorar su historial de derechos humanos.

En el ámbito nacional, si bien Colombia ha sido, principalmente, un país de emigración, es fundamental un cambio de perspectiva. No es suficiente participar en los procesos consultivos en materia de política migratoria enfocada en la salida de nacionales, sino tomar en cuenta experiencias que ayuden a comprender el fenómeno desde sus diferentes aristas, así como llevar a cabo los procesos de inmigración, tránsito y retorno desde los principios de coherencia, igualdad y no discriminación (CSM, 2019).

En el ámbito local, el reto es doble. Por un lado, hacer un llamado a la solidaridad del pueblo colombiano para acoger a los migrantes venezolanos que han debido abandonar su país, así como aportar al proceso de integración, ya que, como se ha señalado, muchos de estos migrantes son colombianos retornados o personas con las que se tienen muchos elementos en común: no hay diferencia lingüística, étnica, cultural o religiosa que genere barreras; además, es importante brindarles un trato digno y condenar prácticas que 
vulneren su integridad. Por el otro, y en un aspecto más institucional, se requiere mayor cooperación y articulación de esfuerzos entre la sociedad civil, el Estado, las organizaciones no gubernamentales, las agrupaciones comunitarias, las personas migrantes y demás actores sociales para que las acciones implementadas tengan un mejor impacto en la población migrante, especialmente con miras a algún proceso de regularización para quienes deseen permanecer de manera temporal, a mediano o a largo plazo.

En este aspecto se destaca la creación del proceso de Registro Administrativo de Migrantes Venezolanos (RAWV), el cual «busca ampliar la información sobre la migración de venezolanos en el país que [...] servirá como soporte para la formulación y diseño de la política integral de atención humanitaria» (UNGRD, 2018, marzo 27). Este es un proceso que permitió, durante los dos meses que estuvo en funcionamiento en 2018, la caracterización sociodemográfica de la población venezolana, tanto regular como irregular, que se encontraba en Colombia. Para ello se habilitaron alrededor de 1019 puntos en 30 departamentos y 413 municipios en todo el país. 23 entidades del orden nacional, departamental y municipal apoyaron esta gestión que, entre otras cosas, ofrecía herramientas para distribuir recursos de cooperación internacional y un manejo más ordenado del ingreso de extranjeros al territorio.

Asimismo, se destaca la creación del Permiso Especial de Permanencia (PEP), el cual ofrece residencia temporal a ciudadanos de Venezuela en Colombia. ${ }^{5}$ Este último funcionó entre julio de 2017 y diciembre de 2018. «En marzo de 2018, se creó también un registro administrativo de migrantes venezolanos, el cual sirvió luego para ampliar el PEP a las personas registradas a partir de agosto y también en diciembre de 2018» (Acosta, Blouin y Freier, 2019 , p. 9). Con estos procedimientos los migrantes pueden permanecer un periodo de noventa días en territorio colombiano, prorrogable hasta por dos años. Con este se ha pretendido que los migrantes puedan acceder a servicios que les garanticen sus derechos básicos: atención sanitaria, educativa y de seguridad, entre otros. Sin embargo, luego de completado el tiempo de dos años, no se ha previsto mecanismo alguno que dé acceso a residencia permanente. De igual manera, es fundamental informar y sensibilizar a

\footnotetext{
${ }^{5}$ Durante las primeras veinticuatro horas de entrada en vigor del servicio se expidieron más de veintidós mil permisos (Migración Colombia, 2017, octubre 26). Para mayo de 2019, 593 mil venezolanos habían accedido a este beneficio (Migración Colombia, 2019, mayo 2).
} 
funcionarios públicos, empresas y a la población en general sobre los cambios en la legislación migratoria y las realidades que estas personas deben enfrentar para contrarrestar las prácticas discriminatorias y las barreras institucionales que se les presentan para acceder a servicios.

\section{Consideraciones finales}

La Conferencia Suramericana sobre Migraciones (CSM) es un proceso consultivo de vital importancia en la región, no solo por contar con la participación de todos los Estados de Suramérica, sino por la oportunidad que representa, en materia de gobernabilidad, la unificación de criterios, experiencias y recursos en la comprensión y atención de fenómenos como el migratorio, especialmente por la contribución que hace al propender por el respeto de los derechos humanos de los migrantes ante la primacía de visiones que equiparan el fenómeno como un problema de seguridad. Sin embargo, el éxodo venezolano le ha planteado un escenario de grandes desafíos que han cuestionado su pertinencia y la posibilidad de afrontar de manera articulada grandes oleadas migratorias.

Durante el desplazamiento masivo intrarregional de casi cuatro millones [224] de ciudadanos de Venezuela han primado las medidas discrecionales, unilaterales de los Estados que, por miedo de desbordar sus sistemas locales ante la magnitud del fenómeno, se han caracterizado por la adopción de enfoques securitistas que les permitan, de cierta manera, lograr una migración ordenada, segura y regular. Para ello, han debido extremar los controles y elevar las exigencias a los migrantes para que puedan acceder a sus territorios. Lo problemático de esto es que muchos de los migrantes venezolanos no cuentan con estos requisitos y mucho menos con los recursos que les permitan obtenerlos, lo que no ha desincentivado la migración, pero sí ha logrado hacer más vulnerable la condición de los migrantes.

Asimismo, la aparición de instancias ad hoc como el «Proceso de Quito» que, si bien responde a una necesidad más focalizada por parte de los Estados que se han visto más impactados en la región ante la llegada de migrantes venezolanos, demuestra poca cooperación y solidaridad entre los países de mayor y menor recepción de la región de cara a su compromiso y participación en la CSM; además, abre interrogantes sobre la apertura de los Estados suramericanos para recibir potenciales migrantes o afrontar fenómenos de igual o mayor magnitud. 
La gobernabilidad migratoria de la región insta a trabajar en conjunto, articuladamente, sin dejar de lado instancias como la CSM que, en últimas, permite socializar experiencias y prácticas que respondan más y mejor a desafíos globales como las migraciones masivas. Es necesario reforzar compromisos y seguir abogando por visiones reformistas que adviertan sobre la necesidad de adoptar medidas para cumplir con los compromisos internacionales en materia de derechos humanos, así como reducir las prácticas securitistas que ponen en riesgo la integridad de los migrantes.

Los retos son múltiples, especialmente para el Estado colombiano, ya que alberga al mayor número de migrantes venezolanos en su territorio. Por ello, deberá apoyar todas las iniciativas que permitan aunar esfuerzos tanto en Suramérica como con en el resto de Latinoamérica para seguir construyendo una gobernabilidad migratoria que dé lugar a respuestas multilaterales que distribuya las cargas, con el fin de evitar colapsar sus sistemas locales, así como el de otros países ante la presión.

Parte de esa tarea consistirá en ratificar su compromiso con la CSM e incentivar a los países que, haciendo parte de esta, no lo hicieron del «Proceso de Quito», para que unan esfuerzos ante esta crisis que representa el éxodo venezolano y los aprendizajes que puede llegar a generar, dado el caso de que se siga extendiendo o que se presenten, desde otros Estados, manifestaciones similares en el futuro.

Finalmente, Colombia tendrá que transformar su visión de país de potencial emigración y adoptar una postura que comprenda el fenómeno desde todas sus aristas; asimismo, trabajar desde sus instituciones, con apoyo de las organizaciones y la sociedad civil y demás actores sociales, para lograr la integración de los migrantes desde sus potencialidades, así como crear mecanismos que no solo gestionen, de manera temporal, el flujo de migración venezolana como el RAWV y el PEP, sino instrumentos que les permitan residir permanentemente $y$, por ende, acceder efectivamente al goce de sus derechos.

\section{Referencias bibliográficas}

1. Acosta, Diego; Blouin, Cécile y Freier, Luisa. (2019). La emigración venezolana: respuestas latinoamericanas. Documentos de Trabajo Fundación Carolina, 3. Recuperado de https://www.fundacioncarolina.es/wp-content/uploads/2019/04/DT_ FC_03.pdf 
2. Agencia de la ONU para los Refugiados (Acnur). (2019, junio 7). Refugiados y migrantes de Venezuela superan los cuatro millones: ACNUR y OIM. Recuperado de https://www.acnur.org/noticias/press/2019/6/5cfa5eb64/refugiados-y-migrantes-devenezuela-superan-los-cuatro-millones-acnur-y.html

3. Álvarez de Flores, Raquel. (2004). La dinámica migratoria colombovenezolana: evolución y perspectiva actual. Geoenseñanza, 9 (2), pp.191-202. Recuperado de http://www.saber.ula.ve/bitstream/handle/123456789/20988/ articulo4.pdf? sequence $=2 \&$ isAllowed $=y$

4. Araujo, Lorena; Eguiguren, María. (2009). La gestión de la migración en los países andinos: entre la securitización y los vínculos diaspóricos. Andina Migrante, 3, pp. 2-10. Recuperado de http://repositorio.flacsoandes.edu.ec/bitstream/10469/197/1/ BFLACSO-AM3-02-Araujo.pdf

5. BBC. (2018, agosto 20). Ataque a venezolanos en Brasil: disturbios en Pacaraima contra campamento de inmigrantes. Recuperado de https:/www.bbc.com/ mundo/noticias-america-latina-45240028

6. Campesi, Giuseppe. (2012). Migraciones, seguridad y confines en la teoría social contemporánea. Revista Crítica Penal y Poder, 3, pp. 1-20.

7. Ceriani, Pablo. (2011). Luces y sombras en la legislación migratoria latinoamericana. Revista Nueva Sociedad, 233, p. 68-86. Recuperado de http://nuso. org/media/articles/downloads/3775_1.pdf

8. Conferencia Suramericana sobre Migraciones (CSM). (2019). Declaración de [226] Quito (Ix Conferencia Sudamericana sobre Migraciones). CSM-Osumi. Recuperado de http://csm-osumi.org/sites/default/files/conferencias/01___declaracion_de_quito.pdf

9. Conferencia Suramericana sobre Migraciones. Observatorio Suramericano sobre Migraciones (CSM-Osumi). (s. f. a). ¿Qué es la CSM? Recuperado de http://csmosumi.org/node/2

10. Conferencia Suramericana sobre Migraciones. Observatorio Suramericano sobre Migraciones (CSM-Osumi). (s. f. b). Conferencias CSM. Recuperado de http:// csm-osumi.org/conferencias-csm

11. Consultoría para los Derechos humanos y el Desplazamiento (Codhes). (2018). Necesidades de protección de las personas venezolanas forzadas a migrar, refugiadas y en riesgo de apatridia en Colombia. Bogotá, D. C.: Codhes.

12. Domenech, Eduardo. (2013). "Las migraciones son como el agua»: Hacia la instauración de políticas de «control con rostro humano». Polis, 35. DOI: 10.4067/ S0718-65682013000200006

13. Düvell, Franck. (2008). Clandestine Migration in Europe. Social Science Information, 47 (4), pp. 479-497. DOI: 10.1177/0539018408096442

14. Ecuador. Ministro de Relaciones Exteriores y Movilidad Humana y Ministra del Interior. Acuerdo Interministerial 0000001. (21 de enero de 2019). Recuperado de https://www.eltelegrafo.com.ec/images/Fotos_ElTelegrafo/ Justicia/2019/enero/25-01-19/acuerdointerministerial.pdf 
15. El Espectador. (2019, noviembre 14). El Espectador le explica: ¿Qué es el proceso de Quito y qué ha hecho por los migrantes? Recuperado de https://www. elespectador.com/noticias/el-mundo/el-espectador-le-explica-que-es-el-proceso-dequito-y-que-ha-hecho-por-los-migrantes-articulo-891137

16. El Mundo. (2019, enero 9). Brasil abandona el pacto migratorio de la ONU. Recuperado de https://www.elmundo.es/internacional/2019/01/09/5c35c928fdddff0 c4e8b4737.html

17. Estupiñán Serrano, Mary Luz. (2013). Acerca de la gobernanza y la gestión migratoria. Crítica del papel de la OIM en el gobierno de la migración internacional y regional. Documentos de Trabajo CLACSO, 33. Recuperado de http://biblioteca. clacso.edu.ar/clacso/posgrados/20131118040902/Serrano.pdf

18. León Cabrera, José María. (2019, enero 28). La xenofobia en Ecuador empuja a migrantes venezolanos a salir del país. The New York Times. Recuperado de https:// www.nytimes.com/es/2019/01/28/espanol/ecuador-ibarra-venezolanos.html

19. Mármora, Lelio. (2010). Modelos de gobernabilidad migratoria. La perspectiva política en América del Sur. Remhu, 18 (35), pp. 71-92.

20. Mármora, Lelio. (2016). Conferencia Suramericana sobre Migraciones 20002015. Buenos Aires: OIM.

21. Martínez Pizarro, Jorge. (2001). Reflexiones sobre la gobernabilidad de la migración internacional en América Latina. Migraciones Internacionales, 1 (1), pp. 89-110. Recuperado de http://www.scielo.org.mx/pdf/migra/v1n1/v1n1a4.pdf

22. Mayeur, Carolina. (1997). Discursos y prácticas migratorias: contradicciones, hipocresías y efectos perversos de las políticas actuales. Migraciones, 2, pp. 9-26. Recuperado de https://revistas.comillas.edu/index.php/revistamigraciones/article/ view/4883/4707

23. Mejía, William. (2012). Colombia y las migraciones internacionales. Evolución reciente y panorama actual a partir de las cifras. Remhu, xx (39), pp. 185-210. DOI: $10.1590 /$ S1980-85852012000200010

24. Mesa, Jesús. (2019, julio 28). Colombia, en riesgo de convertirse en un embudo migratorio. El Espectador. Recuperado de https://www.elespectador.com/noticias/elmundo/colombia-en-riesgo-de-convertirse-en-un-embudo-migratorio-articulo-873245

25. Migración Colombia. (2017, octubre 26). Migración Colombia entrega último balance de venezolanos en Colombia. Recuperado de https://migracioncolombia. gov.co/noticias/176-octubre-2017/migracion-colombia-entrega-ultimo-balance-devenezolanos-en-colombia

26. Migración Colombia. (2019, mayo 2). «Más de 2 millón 260 mil venezolanos se encuentran radicados en el país»: director de Migración Colombia. Recuperado de http://www.migracioncolombia.gov.co/old_site/index.php/es/prensa/comunicados/ comunicados-2019/mayo-2019/11331-mas-de-1-millon-260-mil-venezolanos-seencuentran-radicados-en-el-pais-director-de-migracion-colombia 
27. Milanovic, Branko. (2017). Desigualdad mundial. Un nuevo enfoque para la era de la globalización. México: Fondo de Cultura Económica.

28. Mirra, Alessio. (2018). Las fronteras del siglo xxı. La externalización y la desnaturalización de los espacios de transición. Iberoamérica Social, IX, pp. 111130. Recuperado de https://iberoamericasocial.com/las-fronteras-del-siglo-xxi-laexternalizacion-la-desnaturalizacion-los-espacios-transicion

29. Naranjo Giraldo, Gloria. (2014). Desterritorialización de fronteras y externalización de políticas migratorias. Flujos migratorios irregulares y control de las fronteras exteriores en la frontera España- Marruecos. Estudios Políticos, 45, pp. 13-32. Recuperado de http://aprendeenlinea.udea.edu.co/revistas/index.php/ estudiospoliticos/article/view/20194

30. Perú. Superintendencia Nacional de Migraciones. Resolución 0002702018. (24 de agosto de 2018). Recuperado de https://www.migraciones.gob.pe/wpcontent/uploads/2018/08/RESOLUCION_DE_SUPERINTENDENCIA-000270-2018MIGRACIONES.pdf

31. Podkul, Jennifer \& Kysel, Ian. (2015). Interdiction, Border Externalization, and the Protection of the Human Rights of Migrants. Working Paper Georgetown Law. Retrieved from https:/www.law.georgetown.edu/human-rights-institute/wp-content/ uploads/sites/7/2017/07/2015-WRC-HRI-Submission-to-IACmHR.pdf

32. Sassen, Saskia. (2003). Reubicar la ciudadanía. Posibilidades emergentes en la nueva geografía política. En: Contrageografías de la globalización. Género [228] y ciudadanía en los circuitos transfronterizos (pp. 87-115). Madrid: Traficantes de Sueños.

33. Solanes, Ángeles. (2005). La política de inmigración de la Unión Europea desde tres claves. Arbor, CLXXXI (713), pp. 81-100. DOI: 10.3989/arbor.2005.i713.444

34. Unidad Nacional de Gestión del Riesgo de Desastres (UNGRD). (2018, marzo 27). Registro Administrativo de Migrantes Venezolanos-RAMV. Recuperado de http://portal.gestiondelriesgo.gov.co/Paginas/Slide_home/Registro-Administrativo-deMigrantes-Venezolanos-RAMV.aspx

35. Zapata-Barrero, Ricard y Van Dijk, Teun. (eds.) (2007). Discursos sobre la inmigración en España. Los medios de comunicación, los parlamentos y las administraciones. Barcelona: Fundació Cidob. 